\title{
Crossed Leg Sign Is Associated With Severity of Unilateral Spatial Neglect After Stroke
}

\author{
Gustavo José Luvizutto ${ }^{*}$, Eduardo de Moura Neto², Luiz Antônio de Lima Resende ${ }^{3}$ \\ Hélio Rubens de Carvalho Nunes ${ }^{4}$, Luiz Eduardo Gomes Garcia Betting ${ }^{3}$ \\ and Rodrigo Bazan ${ }^{3}$
}

'Department of Applied Physical Therapy, Institute of Health Sciences, Federal University of Triângulo Mineiro (UFTM), Uberaba, Brazil, ${ }^{2}$ Department of Physical Therapy, Faculty of Human Talent (FACTHUS), Uberaba, Brazil, ${ }^{3}$ Department of Neurology, Psychology and Psychiatry, Botucatu School of Medicine, University Estadual Paulista Júlio de Mesquita Filho (UNESP), Botucatu, Brazil, ${ }^{4}$ Department of Public Health, Botucatu School of Medicine, University Estadual Paulista Júlio de Mesquita Filho (UNESP), Botucatu, Brazil

OPEN ACCESS

Edited by:

Bruce Campbell, University of Melbourne, Australia

Reviewed by: Martin Ebinger, Charité Universitätsmedizin Berlin, Germany Henry Ma,

Monash University, Australia

${ }^{*}$ Correspondence:

Gustavo José Luvizutto gustavo.luvizutto@uftm.edu.br

Specialty section: This article was submitted to Stroke, a section of the journal

Frontiers in Neurology

Received: 08 January 2018 Accepted: 03 April 2018

Published: 18 April 2018

Citation:

Luvizutto GJ, Neto EM, Resende LAL, Nunes HRC, Betting LEGG and Bazan R (2018) Crossed Leg Sign Is Associated With

Severity of Unilateral Spatial Neglect After Stroke.

Front. Neurol. 9:256. doi: 10.3389/fneur.2018.00256
Background: The crossed leg sign in patients with right hemisphere stroke is thought to be associated with perceptual disorders, such as unilateral spatial neglect (USN). The aim of this study was to compare the crossed leg sign with the severity of USN during the acute phase of stroke.

Experimental procedures: This was an observational and prospective clinical study of individuals with a diagnosis of right parietal stroke, as confirmed by neuroimaging. The occurrence of the crossed leg sign, the time at which this occurred after the stroke, and a clinical diagnosis of USN were measured and recorded. The patients' age, sex, and lesion severity, as determined by the National Institutes of Health Stroke Scale and Glasgow coma scale, were included in the analyses as confounding variables. The outcome of interest was the degree of USN, as measured by the cancellation and bisection tests. Binary logistic regression was used to analyze the effect of crossed leg syndrome on the severity of USN. In the adjusted multiple regression model, a $p$-value of $<0.05$ was considered statistically significant.

Results: Overall, 60 patients were included in this study. There were no associations between patient demographics and the presence of the crossed leg sign. There was, however, an association between the crossed leg sign and the absolute value of the deviation in the line bisection test $(B=-0.234 ; p=0.039)$. The crossed leg sign was not associated with other measures of USN.

Conclusion: Based on the results of our study, we can conclude that a crossed leg sign in the acute phase of stroke is associated with USN severity, specifically the misinterpretation of the midline.

Keywords: crossed leg sign, unilateral spatial neglect, hemispatial neglect, stroke, cerebrovascular disease

\section{INTRODUCTION}

Unilateral spatial neglect (USN) is a perceptual disorder that is characterized by an inability to respond to people or objects that are presented contralateral to the lesioned side of the brain when these symptoms cannot be attributed to either motor or sensory deficits (1-3). USN is frequently demonstrated in the clinic as misinterpretation of the midline, which may include head and eye 
deviations on the side contralateral to hemiplegia as well as the crossed leg sign (4-6).

The crossed leg sign was first described in patients with right hemisphere stroke who presented with USN, including cases in which there were associated changes in consciousness (7). It is impossible to detect USN during coma, but frequent rubbing movements of the right leg over the left observed in the first days of clinical evolution may differentiate between patients with torpor and coma. This sign is characterized by an overlap of the right leg over the left as the patient attempts to orient to the midline because there is a loss of spatial orientation of the left space. If the left leg is not perceived or felt to be one's own limb, then abnormal rubbing movements may appear, which may be of predictive value in the development of USN (7).

Our hypothesis is that patients with the crossed leg sign may have a perceptual disorder that causes severe USN after stroke. The aim of this study was to compare the crossed leg sign with the severity of USN in the acute phase of stroke.

\section{MATERIALS AND METHODS}

\section{Study Design, Setting, and Participants}

This was a prospective clinical study in individuals with a diagnosis of stroke that had been confirmed by computed tomography or magnetic resonance imaging. Patients hospitalized in the Emergency Room at the Stroke Unit at the Botucatu Medical School in Botucatu, Brazil were included in this study and were followed from January to December 2016. Stroke diagnoses were established according to the routine guidelines of the hospital. In the hyperacute phase (up to $8 \mathrm{~h}$ following the stroke), the CT scan is performed without contrast and extra and intracranial angiotomography, in addition to perfusion CT. In patients in the acute phase (after $8 \mathrm{~h}$ following the stroke), the CT scan is performed without contrast and extra and intracranial angiotomography. In all subjects, unconfined CT is repeated to obtain a control. Contrast magnetic resonance imaging (T1, T2, flair, and diffusion) is only performed to exclude stroke mimics, neuroinfections, and tumors.

\section{Inclusion and Exclusion Criteria}

Male and female subjects aged 18-85 years with right parietal ischemic stroke confirmed by a CT scan or MRI in the acute phase were included in this study. Individuals with a prior modified Rankin Scale $>1$, aphasia, preexisting dementia, previous visual changes, associated hemianopsia, mechanical orthopedic changes that impair the movement of the lower limb, or other neurological diseases were excluded.

\section{Variables \\ Exposures}

The occurrence of the crossed leg sign, the time at which the sign occurred after the stroke, and a clinical diagnosis of USN were measured and recorded.

\section{Potential Confounding Variables}

The main confounding variables that could potentially be associated with the outcome included age (older individuals have higher severity of USN after stroke), sex (women have worse outcomes of USN in some studies), severity of stroke according to the National Institutes of Health Stroke Scale (NIHSS) (the severity of stroke was associated with higher degree of USN), and the level of consciousness, as measured by the Glasgow coma scale (GCS) (greater degree of USN is expected in individuals with a lower degree of GCS).

\section{Outcomes}

The outcome of interest was the degree of USN, as measured by the cancellation and bisection tests.

\section{Data Sources and Measurement USN Tests}

The degree of USN in the acute phase of stroke was measured using three tests. The first test was the line cancellation test, which measures the proportion of lines omitted from a total of 40 lines that are randomly distributed on one sheet of paper (8). The second test was the star cancellation test, which measures the proportion of stars omitted from a total of 56 smaller stars that are associated with distractors (9). The final test was the line bisection test (LBT), where "the patient was asked to mark the middle of each of 18 lines arranged in three columns of six (on the right, center, and left of the page); the degree of neglect was measured as the distance (in $\mathrm{mm}$ ) between the patient's mark and the middle of the lines" (10). In all USN tests, the examiner placed the exam sheet in front of the patient at a distance of $60 \mathrm{~cm}$ from the glabella to the center of the paper $(11,12)$.

\section{Follow-Up of Crossed Leg Sign}

All patients were observed for their crossed leg behavior in the hyperacute phase (in the emergency room), in the acute and sub-acute phases (in the stroke unit) and at hospital discharge. Crossed leg behavior was defined as having occurred when the patient had the compulsion to cross one leg over the other for two or more consecutive days in three periods of the day. The presence or absence of the sign and the length of time that it remained were recorded. For a confirmed crossed leg sign, the patient must have exhibited $\geq 3$ occurrences of crossed legs on $\geq 2$ consecutive days, with a duration of at least $30 \mathrm{~s}$. The sign was checked every $2 \mathrm{~h}$. Each time, the examiners uncrossed the patient's legs to see if the legs returned to the initial pattern. To establish the time at which the sign disappeared, the absence of the crossed leg sign was considered to be the absence of the compulsion to crossed one leg over the other for two or more consecutive days after the examiners uncrossed the patient's legs.

The patient's severity and topography were blinded for and then followed by five different observers with different levels of clinical experience. Two were consultants (Eduardo de Moura Neto and Hélio Rubens de Carvalho Nunes) and two were neurologists (Luiz Antônio de Lima Resende and Luiz Eduardo Gomes Garcia Betting). The first author (Gustavo José Luvizutto) and the last author (Rodrigo Bazan) recorded the responses from the observers.

To avoid selection bias, all patients with right hemisphere stroke were followed during hospitalization for the crossed leg sign. 


\section{Sampling Plan and Determination of the Minimum Number of Subjects}

This was a convenience sample, and a minimum of 60 subjects was needed to obtain a maximum sampling error of $7.5 \%$ and a confidence level of 95\%. The type I and II error probabilities were 0.05 and 0.20 , respectively, with a SD of the mean of 20 for the left percentage deviation required to detect a difference equal to 10 points in relation to the mean of the left percentage deviation in the LBT.

\section{Statistical Analysis}

Binary logistic regression was used to analyze the effect of crossed leg syndrome on USN level after adjusting for the potential confounding variables (age, sex, severity of stroke, and GCS). In the adjusted multiple regression model, a $p$-value of $<0.05$ was considered statistically significant. The proportion of agreement (presence or absence of cross leg sign) was calculated by the kappa coefficient. A kappa coefficient value less than 0.00 suggests poor agreement, 0.00-.20 suggests slight agreement, 0.21-0.40 suggests fair, $0.41-0.60$ suggests moderate, $0.61-0.80$ suggests substantial, and 0.81-1.00 suggests almost perfect agreement. Statistical analyses were performed with SPSS software version $24.0\left(\right.$ IBM $^{\circledR}$, Chicago, IL, USA).

\section{Ethical Aspects}

This research was approved by an Ethics Committee on Human Research at Botucatu Medical School (number 4223-2012), and written informed consent was obtained from the participants of this study.

\section{RESULTS}

Overall, 150 patients were screened for this study, and 90 were excluded based on the exclusion criteria. Thus, 60 patients were followed and included in the analyses (Figure 1). The demographic and clinical characteristics are shown in Table 1. The proportion of agreement in the observations of the crossed leg sign between the authors was $86 \%$ (74-91\%).

Table 2 describes the clinical and demographic differences between the patients who did and did not present the crossed leg sign. There was no statistically significant difference between the groups regarding the clinical and demographic profile, only an absolute value of midline deviation $(p=0.023)$.

In Figure 2, we show the crossed leg behavior in a patient (Figure 2A) with an objective diagnosis of USN by the LBT (Figure 2B), and the axial apparent diffusion tensor (Figure 2C) and diffusion tensor imaging tractography (Figure 2D) show a lesion in the right frontoparietal region. In the LBT, the lines to the left on the paper were not marked, being compatible with the objective diagnosis of USN.

There was no relationship between any of the patient demographics and the presence of the crossed leg sign. There was a relationship between the crossed leg sign and the absolute value of the deviation on the LBT $(B=-0.234 ; p=0.039)$. There were no associations between the crossed leg sign and the other USN tests (Table 3).

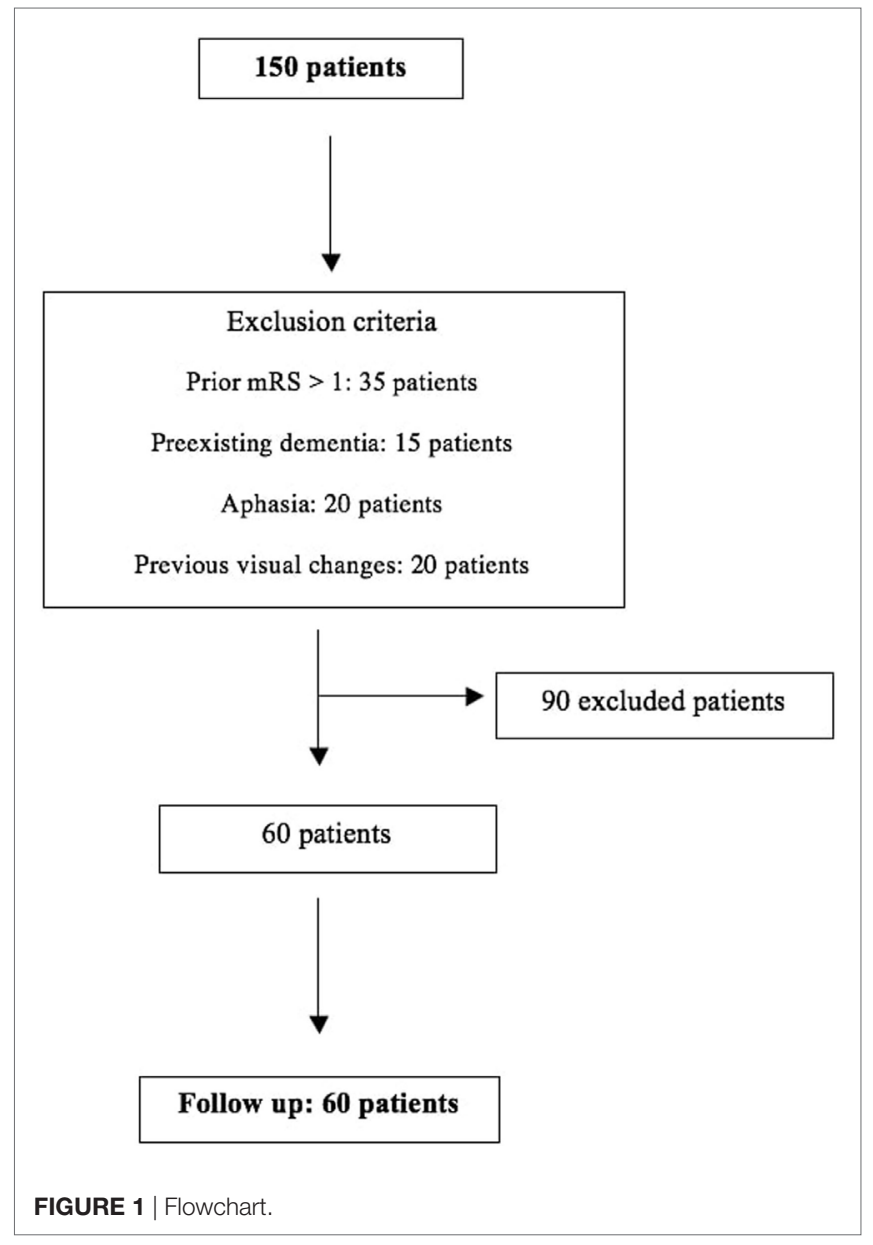

TABLE 1 | Demographic and clinical characteristics of the patients.

\begin{tabular}{|c|c|c|c|c|}
\hline & Min & Max & Mean & SD \\
\hline Age & 34 & 89 & 68.6 & 13.3 \\
\hline \multicolumn{5}{|l|}{ Sex } \\
\hline Male & \multicolumn{4}{|c|}{47 (78.3\%) } \\
\hline Female & \multicolumn{4}{|c|}{23 (21.7\%) } \\
\hline NIHSS & 3 & 24 & 10.7 & 5.2 \\
\hline GCS & 7 & 15 & 12.1 & 2.7 \\
\hline \multicolumn{5}{|l|}{ Cross leg } \\
\hline Yes & \multicolumn{4}{|c|}{$26(43.3 \%)$} \\
\hline No & \multicolumn{4}{|c|}{34 (56.7\%) } \\
\hline LCT & 0 & 40 & 22.5 & 12.1 \\
\hline SCT & 6 & 52 & 33.6 & 12.6 \\
\hline AVD & 15.7 & 98.8 & 66.4 & 22.3 \\
\hline NRD & 12 & 19 & 17.1 & 2.0 \\
\hline
\end{tabular}

NIHSS, National Institutes of Health Stroke Scale; LCT, line cancellation test; SCT, star cancellation test; AVD, absolute value of midline deviation; NRD, number of right deviation of the midline; GCS, Glasgow coma scale.

\section{DISCUSSION}

This study indicates that crossed leg behavior is a factor describing the severity of the development of USN after stroke. It has been shown that cross-legged individuals are twice as likely to present right midline deviations in the LBT. This was an 
TABLE 2 | Demographic and clinical characteristics of the patients with and without crossed leg sign.

\begin{tabular}{lccc}
\hline Variables & $\mathbf{C L}+(\boldsymbol{n}=\mathbf{2 6})$ & $\mathbf{C L}-(\boldsymbol{n}=\mathbf{3 4})$ & $\boldsymbol{p}$ Value \\
\hline Age & $68(34-89)$ & $65(36-82)$ & 0.111 \\
Male & $21(80.7 \%)$ & $24(70.6 \%)$ & 0.074 \\
Female & $5(19.3 \%)$ & $10(29.4 \%)$ & 0.091 \\
NIHSS & $10(3-24)$ & $10(5-20)$ & 0.594 \\
GCS & $12(7-14)$ & $12(7-15)$ & 0.452 \\
LCT & $22(0-40)$ & $18(0-40)$ & 0.294 \\
SCT & $33(6-52)$ & $30(6-48)$ & 0.535 \\
AVD & $66(15-97)$ & $43(5-32)$ & 0.023 \\
NRD & $18(14-19)$ & $16(12-19)$ & 0.192
\end{tabular}

$C L+$, crossed leg sign positive; $C L-$, crossed leg sign negative; NIHSS, National Institutes of Health Stroke Scale; LCT, line cancellation test; SCT, star cancellation test; $A V D$, absolute value of midline deviation; NRD, number of right deviation of the midline; GCS, Glasgow coma scale.

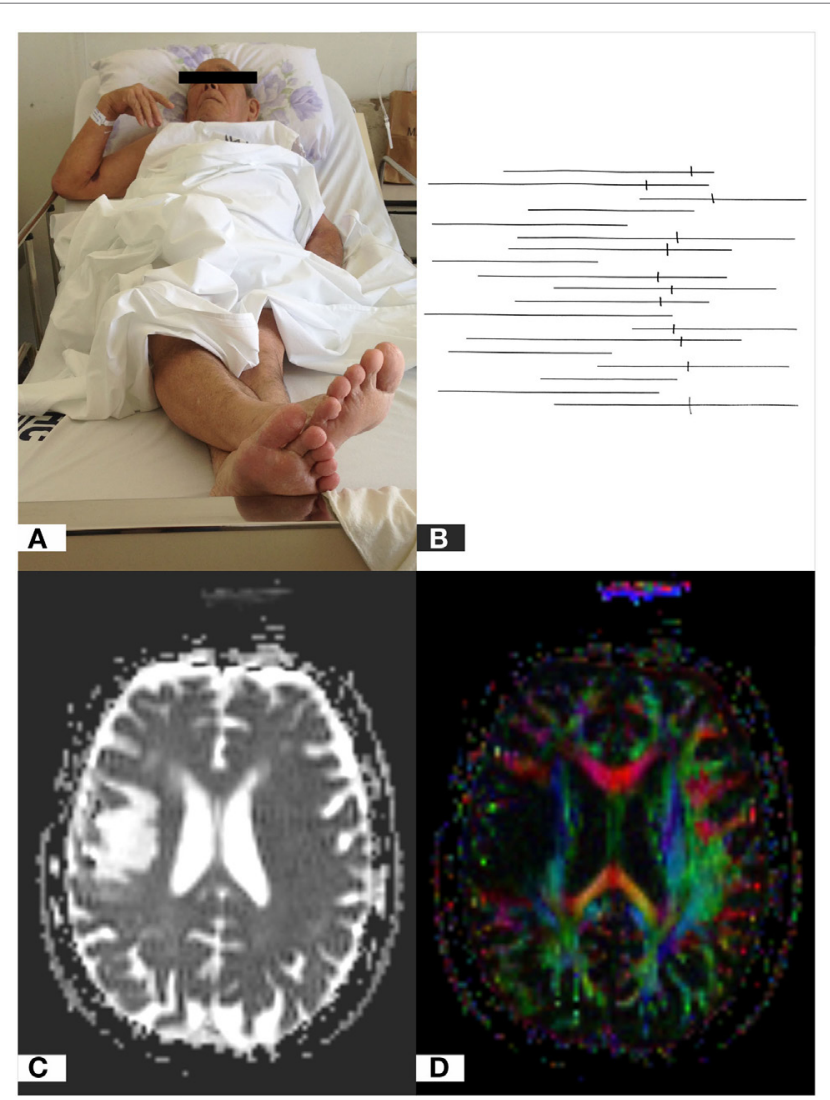

FIGURE 2 | Crossed leg sign in a patient with unilateral spatial neglect (A); line bisection test showing right deviation of the midline (B); axial apparent diffusion coefficient map (C); and diffusion tensor imaging tractography (D) showing a lesion in the right frontoparietal region involving cortico-subcortical portions.

important factor in establishing a causal relationship between leg crossing and the severity of USN and misinterpretation of the midline.

Rémi et al. described 34 patients with leg crossing behavior after stroke and reported that the median duration for this
TABLE 3 | Binary logistic regression according to the crossed leg with USN degree corrected by clinical and anthropometric variables.

\begin{tabular}{lllll}
\hline Variables & $\boldsymbol{B}$ & SE & Wald & $\boldsymbol{p}$ Value \\
\hline Age & -0.128 & 0.08 & 2.545 & 0.111 \\
Sex (male) & -3.856 & 2.187 & 3.109 & 0.078 \\
NIHSS & -0.104 & 0.196 & 0.284 & 0.594 \\
GCS & -0.102 & 0.089 & 0.179 & 0.576 \\
LCT & -0.057 & 0.145 & 0.154 & 0.694 \\
SCT & -0.05 & 0.081 & 0.386 & 0.535 \\
AVD & -0.234 & 0.113 & 4.282 & 0.039 \\
NRD & -0.562 & 0.429 & 1.714 & 0.19 \\
Constant & 45.923 & 19.409 & 5.598 & 0.018
\end{tabular}

Wald, Wald test; NIHSS, National Institutes of Health Stroke Scale; LCT, line cancellation test; SCT, star cancellation test; AVD, absolute value of midline deviation; $N R D$, number of right deviation of the midline; GCS, Glasgow coma scale.

behavior was 15 days and was associated with the best functional prognosis. The authors of that study did not, however, correlate this finding with USN (13). No association was found with better outcomes in this study because the patients with USN presented higher NIHSS values, indicating a higher severity of the neurological condition.

Several textbooks on semiology and neurological examination do not describe the crossed leg sign as a clinical sign in the acute phase of stroke (14-16). In recent years, however, patients with acute stroke in the right hemisphere and changes in consciousness have been reported to present with this behavior during hospitalization, and this appears to be especially true in patients with USN and misinterpretation of the midline (7).

The authors postulate three main theories for leg crossing behavior in the acute phase of stroke in patients with USN. The first is that perceptual disorders with a misinterpretation of the midline, such as anosognosia and asomatognosia, are mainly associated with USN with parietal syndrome of the right hemisphere $(9,17)$. As an individual's consciousness is altered and he/she perceives a foreign body in the bed, such as his/ her left foot or anything in the left hemisphere, the right foot would be expected to repeatedly and compulsively perform the movement of encountering and rejecting this member. The second theory is that when misinterpreting the midline, these patients are always searching for sensorial stimuli. These stimuli increase extrinsic feedback from sensorial input and allow a better interpretation by the parietal lobe $(18,19)$. The final theory is the inter-hemispheric inhibition theory, which suggests that in the acute phase of stroke, a patient with hemiplegia associated with USN will use the compromised lower limb less frequently, which results in less information being transmitted to the injured parietal cortex $(20,21)$. As the injured hemisphere receives less information, it will no longer inhibit the uninjured hemisphere, leading to a hyperactivation of the contralesional hemisphere and an increase in motor activity on the unaffected side.

Based on the results presented, we conclude that the crossed leg sign in the acute phase of stroke is associated with severity of USN, specifically in the misinterpretation of the midline. 


\section{ETHICS STATEMENT}

This research was approved by an Ethics Committee on Human Research at Botucatu Medical School (number 4223-2012).

\section{AUTHOR CONTRIBUTIONS}

GL-literature search, data collection, and writing; EN-writing; $\mathrm{HN}$-data analysis and interpretation; LR - data interpretation and study design; RB and LB—study design.

\section{REFERENCES}

1. Swan L. Unilateral spatial neglect. Phys Ther (2001) 81:1572-80.

2. Verdon V, Vuilleumier P. Neuroanatomy of hemispatial neglect and its functional components: a study using voxel-based lesion symptom mapping. Brain (2010) 133:880-94. doi:10.1093/brain/awp305

3. Kerkhoff G. Spatial hemineglect in humans. Prog Neurobiol (2001) 63:1-27. doi:10.1016/S0301-0082(00)00028-9

4. Prévost MJL. Deviation des yeux et de la tête dans quelques cas d'hémiplégie. Gazette Hebdomadaire de Medecine et de Chirurgie (1865) 41:649-50.

5. Becker E, Karnath HO. Neuroimaging of eye position reveals spatial neglect. Brain (2010) 133:909-14. doi:10.1093/brain/awq011

6. Fruhmann Berger M, Pross RD, Ilg U, Karnath HO. Deviation of eyes and head in acute cerebral stroke. BMC Neurol (2006) 6:49. doi:10.1186/14712377-6-49

7. Bazan R, Fernandes T, Braga G, Luvizutto G, Resende L. A new clinical sign probably associated to left hemiplegia with left hemineglect syndrome: the crossed legs. Arq Neuropsiquiatr (2014) 72(6):418-21. doi:10.1590/ 0004-282X20140043

8. Albert ML. A simple test of visual neglect. Neurology (1973) 23:658-64. doi:10.1212/WNL.23.6.658

9. Halligan PW, Burn JP, Marshall JC, Wade DT. Visuo-spatial neglect: qualitative differences and laterality of cerebral lesion. J Neurol Neurosurg Psychiatry (1992) 55:1060-8. doi:10.1136/jnnp.55.11.1060

10. Schenkenberg T, Bradford DC, Ajax ET. Line bisection and unilateral visual neglect in patients with neurologic impairment. Neurology (1980) 30:509-17. doi:10.1212/WNL.30.5.509

11. Stein JF. Representation of egocentric space in the posterior parietal cortex. Q JExp Physiol (1989) 74:583-606. doi:10.1113/expphysiol.1989. sp003314

12. Marsh NV, Kersel DA. Screening tests for visual neglect following stroke. Neuropsychol Rehabil (1993) 3:245-57. doi:10.1080/09602019308401439

13. Rémi J, Pferfferkorn T, Owens RL, Schankin C, Dehning S, Birnbaum T, et al. The crosseded leg sign indicates a favorable outcome after severe stroke. Neurology (2011) 77:1453-6. doi:10.1212/WNL.0b013e318232abe4

\section{ACKNOWLEDGMENTS}

The authors thank the Neurology Department and Rehabilitation Service of the Botucatu Medical School Hospital for supporting this research.

\section{FUNDING}

This research was supported by FAPESP (2015/14231-0).

14. Déjerine JJ. Sémiologie des affections du système nerveux. Paris: Masson (1914). p. $167-83$.

15. Campbell WW. De Jong's neurological examination. 6th ed. Philadelphia: Lippincott (2005).

16. Posner JB, Saper CB, Schiff ND, Plum F. Plum and Posner's Diagnosis of Stupor and Coma. 4th ed. New York: Oxford University Press (2007).

17. Mesulam MM. Spatial attention and neglect: parietal, frontal and cingulated contributions to the mental representation and attentional targeting of salient extrapersonal events. Philos Trans R Soc Lond B Biol Sci (1999) 354:1325-46. doi:10.1098/rstb.1999.0482

18. Loayza FR, Fernández-Seara MA, Aznárez-Sanado M, Pastor MA. Right parietal dominance in spatial egocentric discrimination. Neuroimage (2011) 55(2):635-43. doi:10.1016/j.neuroimage.2010.12.011

19. Bonan I, Chochina L, Moulinet-Raillon A, Leblong E, Jamal K, ChalloisLeplaideur S. Effect of sensorial stimulations on postural disturbances related to spatial cognition disorders after stroke. Neurophysiol Clin (2015) 45(4-5): 297-303. doi:10.1016/j.neucli.2015.09.006

20. Nitsche MA, Paulus W. Excitability changes induced in the human motor cortex by weak transcranial direct current stimulation. J Physiol (2000) 527(Pt 3): 633-9. doi:10.1111/j.1469-7793.2000.t01-1-00633.x

21. Bindman LJ, Lippold OCJ, Redfearn JW. The action of brief polarizing currents on the cerebral cortex of the rat (1) during current flow and (2) in the production of long-lasting after-effects. J Physiol (1964) 172:369-82. doi:10.1113/ jphysiol.1964.sp007425

Conflict of Interest Statement: The authors declare that there is no conflict of interest regarding the publication of this article.

Copyright (c) 2018 Luvizutto, Neto, Resende, Nunes, Betting and Bazan. This is an open-access article distributed under the terms of the Creative Commons Attribution License (CC BY). The use, distribution or reproduction in other forums is permitted, provided the original author(s) and the copyright owner are credited and that the original publication in this journal is cited, in accordance with accepted academic practice. No use, distribution or reproduction is permitted which does not comply with these terms. 